\title{
Introduction to International Ethical Standards Related to Genetics and Genomics
}

\author{
Seon-Hee Yim $^{1 *}$, Yeun-Jun Chung ${ }^{2 * *}$ \\ ${ }^{1}$ Department of Medical Education, Integrated Research Center for Genome Polymorphism, The Catholic University of Korea \\ College of Medicine, Seoul 137-701, Korea, ${ }^{2}$ Department of Microbiology, Integrated Research Center for Genome Polymorphism, \\ MRC, The Catholic University of Korea College of Medicine, Seoul 137-701, Korea
}

The rapid advances in genetic knowledge and technology raise various, sometimes unprecedented, ethical dilemmas in the scientific community as well as the public realm. To deal with these dilemmas, the international community has prepared and issued ethical standards in various formats. In this review, seven international standards regarding genetics and genomics will be briefly introduced in chronological order. Critical reflections on them will not be provided in this review, and naturally, they have their own problems and shortcomings. However, a common set of the principles expressed in them will be highlighted here, because they are still relevant, and many of them will be more relevant in the future. Some of the interesting contents will be selected and described. After that, the morality of one recent event related to whole-genome sequencing and person-identifiable genetic data will be explored based on those international standards.

Keywords: ethics, genetics, genomics

\section{Preamble}

Recently, there was a very unique bio-art exhibition by New York-based artist Heather Dewey-Hagborg, titled "Stranger Visions" [1]. She collected samples from discarded chewing gum, strands of hair, and cigarette butts around New York City. She took these items to Genspace, a do-it-yourself community biology laboratory, where DNA was extracted from each of the objects. By sequencing specific genomic regions and cross-referencing the results with published data, she was able to create 3-dimensional (3D) sculpted portraits of her anonymous donors using a 3D printer. She said that this work is designed to stimulate a cultural dialog about genetic surveillance. However, this provocative art project surely raises a question: Is it ethical?

To find an answer to this question, as a starting point, it would be helpful to review some major conventions, resolutions, declarations, or guidelines issued by international public organizations, such as the United Nations (UN); the United Nations Educational, Scientific and Cultural Organization (UNESCO); and the Council of Europe. These norms have been providing the principles and recommendations that guide the member states in their legislation and policy. They are worth reviewing, because, as Marie Curie once wrote, "science is essentially international." Knowledge, technologies, and money-capital and research fund - in the bioscience field cross borders freely and very quickly. In this review, seven international standards relevant to genetics and genomics will be introduced briefly in chronological order with some background information, and the possible answer to the questions with regard to the bio-art project will be provided after that.

\section{The Declaration of Inuyama (July 1990, CIOMS)}

In July 1990, just a couple of months before the Human Genome Project (HGP) officially began, the Council for International Organizations of Medical Sciences (CIOMS) held the conference, titled "Genetics, Ethics, and Human Values: Human Genome Mapping, Genetic Screening, and Therapy," in Tokyo and in Inuyama City, Japan. The Confe- 
rence was co-sponsored by the World Health Organization (WHO) and UNESCO. Here, the Conference produced the Declaration consisting of eight statements. The following information is the main content of the Declaration [2].

The Conference agreed that the HGP would present no inherent ethical problems but was concerned about genetic testing, which would be available through the project, since the identification and sequencing of new genes can expand the scope for diagnostic tests. The Declaration emphasizes the importance of the welfare of the person tested and the confidentiality of the test results. For this, adequate genetic counseling is recommended. Also, the Declaration requires that the needs of developing countries should obtain their due share of the benefits that ensue from the HGP.

Regarding gene therapy, the Declaration states that it should be limited to conditions that cause significant disability and not employed simply to enhance or suppress cosmetic, behavioral, or cognitive traits that are not related to any recognized human disease. Regarding germ-line gene therapy, the Declaration states that "continued discussion of both its technical and ethical aspects is essential and that, before germ-line therapy is undertaken, its safety must be well established, for changes in germ cells would affect the descendants of patients.'

The Declaration acknowledges public concern about the growth of genetic knowledge, which is partly caused by a misconception: the genetic knowledge reveals an essential aspect of humanness (i.e., genetic essentialism); it may reduce human beings to mere base pairs of DNA (i.e., genetic reductionism). To correct this misconception, the Declaration recommends education of the public and open discussion. To ensure the setting and observance of ethical standards, continuous multidisciplinary and transcultural dialog and ethical sensitivity in policy-making are recommended.

\section{The Committee of Ministers of the Council of Europe Recommendation No. R (92) 3 on Genetic Testing and Screening for Health Care Purposes (February 1992)}

The Council of Europe, set up in 1949, is a pan-European intergovernmental organization that aims at fostering a closer cooperation among 47 Member States, including the European Union (EU) members. Being aware that the introduction of genetic testing and screening can arouse anxiety, the Council decided that 'it is desirable to give assurances as to their proper use.' The Committee recommended 11 principles regarding: informing the public, quality of genetic services, counseling and support, equality of access, nondiscrimination, self-determination, non-compulsory nature of tests, insurance, professional secrecy, storage of genetic information, and unexpected findings. The following information is some content of the Recommendations, which are becoming more relevant today [3].

Like the Declaration of Inuyama, this recommendation also emphasizes the need to educate the health care professionals and the general public about the importance of genetic factors to health and the implications of genetic testing-medical, legal, social, and ethical. It encourages including this subject in curricula for general and higher education and in professional training.

It mentions the dangers of discrimination and social stigmatization based on genetic information and states that the third party, such as insurers, should not have the right to require genetic testing or to inquire about results of previous tests as a pre-condition for an insurance contract, health service benefits, family allowances, marriage, or employment.

In spite of the emphasis on the confidentiality of test results and professional secrecy, in the case of a severe genetic risk for other family members, consideration should be given to informing family members about matters relevant to their health or that of their future children. However, there is no mention of the right not to know of the family members in this Recommendation. It also recommends that unexpected findings may be communicated to the person tested only if they are of direct clinical importance to the person or the family. Communication of unexpected findings to family members of the person tested should be authorized by law if the person tested refuses expressly to inform them, even though his life is in danger.

\section{The Council of Europe Convention for the Protection of Human Rights and Dignity of the Human Being with regard to the Appli- cation of Biology and Medicine: Conven- tion on Human Rights and Biomedicine (April 1997)}

This Convention is legally binding in the European countries that have ratified it and serves as a reference instrument for the EU and for other international organizations. The aims of the Convention are to protect the dignity and identity of all human beings and to guarantee everyone, without discrimination, respect for their integrity and other rights and fundamental freedoms with regard to the application of biology and medicine. Regarding the concept of the primacy of fundamental human rights, this Convention succeeds the Convention for the Protection of Human Rights and Fundamental Freedoms (1950) and expands the concept to the fields of biology and medicine. 
Article 2 clearly states that the interests and welfare of the human being shall prevail over the sole interest of society or science. The following information is the content of the Convention that is relevant to genetics and genomics [4].

There is one separate chapter dedicated to the human genome consisting of four articles, which address issues, such as: discrimination against a person on grounds of his or her genetic heritage; predictive genetic tests; and interventions on the human genome, etc. The Convention states that predictive genetic tests may be performed only for health purposes or for scientific research linked to health purposes and are subject to appropriate genetic counseling. Interventions on the human genome may only be undertaken for preventive, diagnostic, or therapeutic purposes and only if its aim is not to introduce any modification in the genome of any descendants. Article 10 mentions the right to be informed about his or her health and also acknowledges the right not to know.

\section{Universal Declaration on the Human Ge- nome and Human Rights (November 1997, UNESCO)}

The Declaration, consisting of 6 sections and 25 articles, was adopted unanimously on November 11, 1997 and endorsed by the UN General Assembly on December 9, 1998. Its Guidelines for the implementation were also endorsed on November 16, 1999. The aims of the Declaration are to promote and develop ethical studies and the actions arising out of them on the consequences of scientific and technological progress in the fields of biology and genetics, within the framework of respect for human rights and fundamental freedoms. UNESCO recognizes that research on the human genome and the resulting applications open up vast prospects for progress in improving the health of individuals and of humankind as a whole. However, it emphasizes that such research should fully respect human dignity, freedom, and human rights, as well as the prohibition of all forms of discrimination based on genetic characteristics. The following information is the main content of the Declaration [5].

The Declaration covers the issues of human dignity, the human genome, research on the human genome, conditions for the exercise of scientific activity, solidarity, and international cooperation, etc.

Article 1 states that the human genome underlies the fundamental unity of all members of the human family, as well as the recognition of their inherent dignity and diversity. It even declares that the human genome is the heritage of humanity in a symbolic sense. Article 2 prohibits genetic discrimination and states that human dignity makes it imperative not to reduce individuals to their genetic characteristics and to respect their uniqueness and diversity. Article 3 acknowledges that the human genome can be expressed differently according to each individual's natural and social environment, including the individual's state of health, living conditions, nutrition, and education, rejecting genetic determinism. Article 4 declares that the human genome in its natural state shall not give rise to financial gains. Article 10 affirms that no research or research applications concerning the human genome should prevail over respect for the human rights, fundamental freedoms, and human dignity of individuals or of groups of people. Article 11 prohibits practices that are contrary to human dignity, such as reproductive cloning of human beings, but there is no mention of therapeutic cloning.

\section{International Declaration on Human Ge- netic Data (October 2003, UNESCO)}

The Declaration consists of five sections and 27 articles and seems to be more relevant to researchers in the fields of genetics and genomics than the other six standards. The aim of this Declaration is to ensure the respect of human dignity and protection of human rights and fundamental freedoms in the collection, processing, use, and storage of human genetic data, human proteomic data, and of the biological samples from which they are derived, in keeping with the requirements of equality, justice, and solidarity, while giving due consideration to freedom of thought and expression, including freedom of research. It is also very relevant today, since the importance of human genetic data for economic and commercial purposes increases and the growing amount of personal data collected makes genuine irretrievability increasingly difficult. The following is the content of the Declaration [6].

This Declaration covers various practical issues: withdrawal of consent; the right to know or right not to know of research results; access to his or her own data; privacy and confidentiality; circulation and international cooperation; sharing of benefits; storage and destruction; and crossmatching.

Article 4 describes that human genetic data have a special status on account of their sensitive nature: they can be predictive of genetic predispositions concerning individuals, and the power of predictability can be stronger than assessed at the time of deriving the data; they may have a significant impact on the family, including offspring, extending over generations, and in some instances on the whole group; they may contain information, the significance of which is not known at the time of the collection of biological samples; and they may have cultural significance for persons or groups. 
Article 7 requires that every effort should be made to ensure that human genetic data and human proteomic data are not used in a way that leads to discrimination or stigmatization. In this regard, appropriate attention should be paid to the findings of population-based genetic studies and behavioral genetic studies and their interpretations. Article 19 emphasizes the need to share the benefits resulting from the use of human genetic and proteomic data or biological samples collected for medical and scientific research. It describes the various forms of benefits: special assistance to the persons and groups that have taken part in the research; access to medical care; provision of new diagnostics, facilities for new treatments, or drugs stemming from the research; support for health services; capacity-building facilities for research purposes; and development and strengthening of the capacity of developing countries to collect and process human genetic data.

\section{Universal Declaration on Bioethics and Hu- man Rights (October 2005, UNESCO)}

It was the first time in the history of bioethics that member states committed themselves and the international community to respect and apply the fundamental principles of bioethics set forth within a single text consisting of 28 articles. This Declaration addresses ethical issues related to medicine, life sciences, and associated technologies as applied to human beings, taking into account their social, legal, and environmental dimensions. The aims of this Declaration include: to recognize the importance of freedom of research and the benefits derived from scientific and technological developments, while stressing the need for such research and developments to occur within the framework of ethical principles; to respect human dignity, human rights, and fundamental freedoms; to safeguard and promote the interests of the present and future generations; and to underline the importance of biodiversity and its conservation as a common concern of humankind. The following information is the content of the Declaration that is relevant to genetics and genomics [7].

Article 16 emphasizes the impact of life sciences on future generations, including their genetic constitution. To protect the environment, the biosphere, and biodiversity, Article 17 encourages to pay due regard to the interconnection between human beings and other forms of life, to the importance of appropriate access and utilization of biological and genetic resources, to respect for traditional knowledge, and to the role of human beings. Article 21 requires that, in transnational practices, States should take appropriate measures, both at the national and international levels, to combat bioterrorism and illicit traffic in organs, tissues, samples, genetic resources, and genetic-related materials. However, some experts criticize the process of drafting the Declaration, which excluded a necessary group of stakeholders, and claim that the Declaration therefore fails to provide the guidance that can be readily applied in different settings [8].

\section{Additional Protocol to the Convention on Human Rights and Biomedicine concerning Genetic Testing for Health Purposes (No- vember 2008)}

To supplement the principles set forth in the Convention on Human Rights and Biomedicine (1997), the Council of Europe Steering Committee on Bioethics developed the Additional Protocol concerning genetic testing for health purposes, consisting of 9 chapters and 28 articles. This first international, 'legally binding' instrument concerning genetic testing for health purposes was adopted by the Committee of Ministers of the Council of Europe. The Protocol lays down principles regarding the quality of genetic services, clinical utility, individualized supervision, genetic counseling, consent, privacy, right to information, and genetic screening programs, etc. The Protocol does not apply to genetic tests carried out on the human embryo or fetus and to genetic tests carried out for research purposes, which are covered by another Additional Protocol to the Convention. Among the articles, two articles are provided below that have never been addressed in the previous six documents [9].

A particular emphasis on the clinical utility as an essential criterion for deciding to offer a genetic test and on individualized medical supervision has implications for tests that are provided outside the clinical setting, especially for directto-consumer predictive genetic testing. Another interesting feature is that there is a whole chapter dedicated to the genetic testing on persons not able to consent. The Protocol provides that, for the benefit of family member(s), when it is not possible to contact a person for a genetic test on his or her biological material previously sampled for another purpose, the law may allow the test to be carried out if the expected benefit can not be otherwise obtained and the test can not be deferred. Also, the Protocol provides that a genetic test for the benefit of other family members may be carried out on biological samples removed from the body of a deceased person, or removed when he or she was alive, from a person now deceased, only if the consent or authorization required by law has been obtained.

\section{Summary and Answers to the Questions}

Although there are more international norms besides the seven standards introduced in this article and will be more, 
Table 1. Principles and suggestions common to the seven instruments

\section{Principles and suggestions}

Human dignity, human rights, and fundamental freedoms should be fully respected.

The interests and welfare of the individual should have priority over the interest of science or society.

Protection of privacy and confidentiality is very important regarding genetic information, which has a special status on account of their sensitive nature.

Voluntary informed consent has its utmost importance in the protection of these fundamental values.

Equal access to genetic testing and sharing of the benefits from research is encouraged.

Genetic discrimination and stigmatization based on genetic reductionism and determinism should be prohibited.

Providing tests or procedures that are not medically indicated should be refrained.

Education of researchers, health professionals, and general public is important.

Continuous, open, multidisciplinary, transcultural dialog is important as the means of ensuring the setting and observance of ethical standards

a set of currently recognized, common ethical principles regarding genetics and genomics can be drawn from these standards (Table 1). There are hardly any clashes over the main principles or attitudes towards the human genome among these norms. Small differences, which are mostly found in details, have resulted from adding new principles and details, rather than changing or negating the previously declared principles.

Keeping these principles in mind, let us go back to DeweyHagborg's project. The action concerned is the genetic testing of abandoned DNA without the donor's consent. Did the artist violate their human rights, especially fundamental freedom, by testing their genomes without consent? Since the artist does not know their identity, she could not obtain their consent. One protocol provides ideas for cases when it is not possible to contact a person for a genetic test. It says that the law may allow the test to be carried out when the testing is for the benefit of family member(s) on his or her biological material previously sampled for another purpose and when the expected benefit cannot be otherwise obtained and where the test cannot be deferred [9]. Therefore, DeweyHagborg's action seems unlikely to be justified. In addition, from a legal perspective, New York's law outlaws most DNA testing without written consent, and the United Kingdom also outlawed non-consensual DNA testing in 2006. However, the legal status of DNA retrieved in the environment is uncertain in many jurisdictions. Another important question is whether the testing infringed their privacy. Since the individuals concerned are unlikely to be recognizable from the sculptures, the artist argues that her project does not invade privacy. Then, what if it is technically possible to identify the donor or is possible in the near future? Does it change the nature of the action? To all these questions, there may not be one correct answer at all or there can be many alternative answers to each question. For most ethical dilemmas, the first step to find good answers to them is to have ethical sensitivity-the ability to perceive ethical problems as ethical problems. After that, continuous, open, multidisciplinary, transcultural dialog will greatly help our journey, and our colleagues will be very reliable companions.

\section{Acknowledgments}

This study was supported by the Korea Healthcare Technology R\&D Project (A092258) and a grant from National Research Foundation of Korea (2012R1A5A2047939).

\section{References}

1. Aldhous P. Artworks highlight legal debate over 'abandoned' DNA. New Sci 2013;218:12.

2. The Declaration of Inuyama and reports of the working groups. Hum Gene Ther 1991;2:123-129.

3. Council of Europe. Recommendation No. R(92)3 of the Committee of Ministers to member states on genetic testing and screening for health care purposes. J Int Bioethique 1992;3:255-257.

4. Council of Europe. Convention for the protection of human rights and dignity of the human being with regard to the application of biology and medicine: convention on human rights and biomedicine. Strasbourg: Council of Europe, 1997. Accessed 2013 Oct 4. Available from: http://conventions.coe. int/Treaty/en/Treaties/Html/164.htm.

5. United Nations Educational, Scientific and Cultural Organization. Universal declaration on the human genome and human rights. Paris: UNESCO, 1997. Accessed 2013 Oct 5. Available from: http://www.unesco.org/new/en/social-andhuman-sciences/themes/bioethics/human-genome- and-human-rights.

6. United Nations Educational, Scientific and Cultural Organization. International declaration on human genetic data. Paris: UNESCO, 2003. Accessed 2013 Oct 5. Available from: http://www.unesco.org/new/en/social-and-human-sciences/themes/bioethics/human-genetic-data/.

7. United Nations Educational, Scientific and Cultural Organization. Universal declaration on bioethics and human rights. Paris: UNESCO, 2005. Accessed 2013 Oct 6. Available from: 
http://www.unesco.org/new/en/social-and-human-sciences/themes/bioethics/bioethics-and-human-rights.

8. Macpherson CC. Global bioethics: did the universal declaration on bioethics and human rights miss the boat? J Med Ethics 2007;33:588-590.
9. Council of Europe. Additional protocol to the convention on human rights and biomedicine concerning genetic testing for health purposes. Strasbourg: Council of Europe, 2008. Accessed 2013 Oct 3. Available from: http://conventions. coe.int/Treaty/en/Treaties/Html/203.htm. 